\title{
ORIGINAL ARTICLE \\ Mating system contributes only slightly to female maintenance in gynodioecious Geranium maculatum (Geraniaceae)
}

\author{
ML Van Etten ${ }^{1,2}$, AC Deen ${ }^{1}$, JL Hamrick ${ }^{1}$ and S-M Chang ${ }^{1}$ \\ Gynodioecy, the co-occurrence of female and hermaphroditic individuals within a population, is an important intermediate in \\ the evolution of separate sexes. The first step, female maintenance, requires females to have higher seed fitness compared with \\ hermaphrodites. A common mechanism thought to increase relative female fitness is inbreeding depression avoidance, the \\ magnitude of which depends on hermaphroditic selfing rates and the strength of inbreeding depression. Less well studied is the \\ effect of biparental inbreeding on female fitness. Biparental inbreeding can affect relative female fitness only if its consequence \\ or frequency differs between sexes, which could occur if sex structure and genetic structure both occur within populations. To \\ determine whether inbreeding avoidance and/or biparental inbreeding can account for female persistence in Geranium \\ maculatum, we measured selfing and biparental inbreeding rates in four populations and the spatial genetic structure in six \\ populations. Selfing rates of hermaphrodites were low and did not differ significantly from zero in any population, leading to \\ females gaining at most a $1-14 \%$ increase in seed fitness from inbreeding avoidance. Additionally, although significant spatial \\ genetic structure was found in all populations, biparental inbreeding rates were low and only differed between sexes in one \\ population, thereby having little influence on female fitness. A review of the literature revealed few sexual differences in \\ biparental inbreeding among other gynodioecious species. Our results show that mating system differences may not fully \\ account for female maintenance in this species, suggesting other mechanisms may be involved. \\ Heredity (2014) 113, 464-470; doi:10.1038/hdy.2014.48; published online 14 May 2014
}

\section{INTRODUCTION}

Gynodioecy, the co-occurrence of female and hermaphroditic individuals, is the most likely stepping stone from having both male and female functions within the same flower to partitioning the two functions on separate plants. This is one of the most important transitions in plant breeding system evolution and scientists since Darwin have been interested in the factors involved (for example, Darwin, 1897; Charlesworth and Charlesworth, 1978; Barrett, 2010). One factor that is critical for this transition is the relative seed fitness of females. Specifically, females need higher seed fitness than hermaphrodites to be maintained in populations, the amount ranging from slightly 1 to $2 \times$ depending on the genetic control of sex (Charlesworth and Charlesworth, 1978; Gouyon et al., 1991; Bailey et al., 2003). Additionally, higher relative female seed fitness can increase female frequency in a population, and also strengthen selection for hermaphrodites to become increasingly male (Charlesworth and Charlesworth, 1978; Gouyon et al., 1991). Because of its importance, many studies have investigated the mechanisms and magnitude of higher female relative seed fitness in gynodioecious species (reviewed in Shykoff et al., 2003; Dufay and Billard, 2012).

One mechanism that has been proposed for increasing female seed fitness is inbreeding depression avoidance. Inbreeding depression, the reduction of fitness of offspring from matings between related individuals, can be caused by selfing (mating with self) or biparental inbreeding (matings between relatives). Because females cannot selfpollinate and therefore do not incur inbreeding depression through selfing, they should produce, on average, more and/or better seeds than hermaphrodites if the frequency of selfing $(s)$ in hermaphrodites is high and inbreeding depression $(\delta)$ is severe. For example, in Silene vulgaris, high inbreeding depression $(\delta \sim 0.50$; Glaettli and Goudet, $2006)$ and high selfing ( $s \sim 0.76$; Miyake and Olson, 2009) led to a $60 \%$ increase in female fitness. In many gynodioecious species, hermaphrodites self to a certain degree (reviewed in Collin and Shykoff, 2003) and generally have high inbreeding depression (Mutikainen and Delph, 1998), suggesting that inbreeding avoidance potentially has an important role in determining female fitness advantage (FA).

Less well studied is the extent of biparental inbreeding and its effect on female FA. Biparental inbreeding can occur in both females and hermaphrodites and can also result in inbreeding depression (for example, Mutikainen and Delph, 1998; Delph, 2004; Chang, 2007). In fact, biparental inbreeding rates in females can reach as high as $40 \%$ in some species (for example, Maki, 1993; Kohn and Biardi, 1995), suggesting that biparental inbreeding could have a role in determining female FA if the frequency and/or fitness consequences of biparental inbreeding differ between sexes. Differences in the frequency of

${ }^{1}$ Department of Plant Biology, University of Georgia, Athens, GA, USA and ${ }^{2}$ Department of Ecology, Institute of Agriculture and Environment, Massey University, Palmerston North, New Zealand

Correspondence: Dr M Van Etten, Department of Ecology, Institute of Agriculture and Environment, Massey University, Palmerston North 4442, New Zealand. E-mail: m.vanetten@massey.ac.nz

Received 28 November 2013; revised 23 March 2014; accepted 27 March 2014; published online 14 May 2014 
biparental inbreeding may be facilitated when sexes are not randomly distributed (spatial sex structure) and individuals are surrounded by genetically related individuals (positive spatial genetic structure). For example, in sex structured populations, females are surrounded by other females and, hence, pollen they receive is likely to have been transported from further away. In contrast, hermaphrodites are more likely to be surrounded by other hermaphrodites and, hence, can receive genetically related pollen from near neighbors leading to biparental inbreeding. Sex structure has been found in several gynodioecious species (Olson et al., 2006; De Cauwer et al., 2010; De Cauwer et al., 2012) and spatial genetic structure is common in plants (reviewed in Heywood, 1991; Epperson, 1993), suggesting that differences in biparental inbreeding rates could be common, and therefore could have an important role in determining relative female advantage.

To determine the contributions of both selfing and biparental inbreeding to the maintenance of females, we estimated selfing and biparental inbreeding rates and spatial genetic structure in populations of G. maculatum. Previous studies in this species have shown that inbreeding depression is strong, is early acting, and occurs for both selfing and biparental inbreeding (Chang, 2007). Also, populations show spatial sex structuring (Van Etten and Chang, 2009), potentially facilitating differences in levels of biparental inbreeding. Using allozyme markers and populations at the extreme ends of the range of observed sex ratios, we investigated (1) the degree of FA that females gained through inbreeding avoidance, (2) whether spatial genetic structure occurred within populations and (3) whether differences between sexes existed in biparental inbreeding rates. We applied our results to explore whether the female advantage from selfing was sufficient to explain their maintenance, given the two common types of genetic control, and if differences in biparental inbreeding could affect the maintenance of gynodioecy in this and other species.

\section{MATERIALS AND METHODS}

\section{Study species}

G. maculatum is a gynodioecious, rhizomatous perennial occurring in eastern North America (Ågren and Willson, 1991). Populations are located predominantly in the understory and contain from five to more than a thousand flowering individuals (SMC, personal observation.). Flowering begins in early spring, with individuals producing on average six flowers per inflorescence (Chang, 2006). Flowers are visited by generalist pollinators including bees, flies and butterflies. Each fruit can produce at most five seeds, which are dispersed by elastic dehiscence of the schizocarp to an average of $3 \mathrm{~m}$ from the maternal plant (Stamp and Lucas, 1983). Based on field and greenhouse observations, hermaphrodites generally produce $<10 \%$ female progeny, whereas females produce about equal proportions of female and hermaphroditic progeny (Van Etten and Chang, unplublished; Chang, 2007), suggesting that sex is under nuclear or cyto-nuclear control. Females have small aborted anthers and smaller petal sizes compared with hermaphrodites (Ågren and Willson, 1991; Chang, 2006). Local populations near Athens, GA, USA range in female frequency from 0 to $50 \%$ (Chang, 2006).

\section{Populations}

Seven populations, four with no females (monomorphic; M1-M4) and three with females (dimorphic; D1-D3), were selected (Table 1). For mating system analyses we sampled two populations of each type (M3, M4, D1 and D3), and for the genetic structure analyses we sampled three populations of each type (M1, M2, M3, D1, D2 and D3). All populations were located in Clarke County, GA, USA except population M4, which was located in adjacent Oconee County, GA, USA (Table 1), with the distance between populations ranging from $100 \mathrm{~m}$ to $5.44 \mathrm{~km}$. Populations varied in size, density and sex ratio (Table 1). Populations D1 and D3 had been studied previously in Chang (2006; 2007) and designated as OT and MP, respectively.

\section{Mating system sampling}

Seeds for mating system analyses were collected in Spring 2004 for D1, D3 and M3, and in Spring 2008 for M4. In each population, seeds were collected from 16 to 31 plants of each sex (where applicable) by covering the entire infructescence with mesh bags until seeds were mature, resulting in seeds from multiple fruits. For each individual, 9-20 seeds were randomly selected for extraction (see Table 2 for sample sizes). Half of the seeds from population D1 were scarified, germinated, and grown in the greenhouse. This procedure, however, was later abandoned because germination rates were low. For the remaining seeds from D1 and for all of the seeds from D3, M3 and M4, seeds were used directly for allozyme extraction. These seeds were prepared by scarifying the seed coat, soaking the seeds in de-ionized water at $5{ }^{\circ} \mathrm{C}$ for $24 \mathrm{~h}$ to soften the seed coat, and carefully removing the seed coat before placing the seeds at $5{ }^{\circ} \mathrm{C}$ for an additional $1-2$ weeks before extraction. Except the seed coat, mature seeds in this species contain predominantly embryonic tissues, thus, representing the progeny genotype.

\section{Genetic structure sampling}

Strategies to obtain leaf samples for $\sim 96$ flowering individuals of each sex from each population differed by population because of the variation in population size and density. To sample throughout the populations, one (M3), two (D3) or three (M1, M2, D1, D2) 1-m-wide transects were placed across a population. For populations with too few plants within the transects (M2, M3 and D2), transects were widened until they contained the appropriate

Table 1 Population descriptions including the location, percentage of females $(\% F)$, the approximate number of flowering ramets, the number of individuals sampled for the spatial genetic structure analyses $\left(N_{\mathbb{S}}\right)$ if appropriate, adult density and the average distance between neighboring plants

\begin{tabular}{|c|c|c|c|c|c|c|c|}
\hline Population & Location & GPS coordinates & $\% \mathrm{~F}$ & $\begin{array}{c}\text { Approximate } \\
\text { number of adults }\end{array}$ & $\mathrm{N}_{S}$ & $\begin{array}{l}\text { Adult density } \\
\left.\text { (per } \mathrm{m}^{2}\right)\end{array}$ & $\begin{array}{c}\text { Nearest neighbor } \\
\text { distance (cm) (s.e.) }\end{array}$ \\
\hline \multicolumn{8}{|c|}{ Monomorphic populations } \\
\hline M1 & Oconee Forest/Lake Herrick & $33^{\circ} 55^{\prime} 44.26^{\prime \prime} \mathrm{N}, 83^{\circ} 22^{\prime} 25.78^{\prime \prime} \mathrm{W}$ & 0 & 200 & 96 & 1.343 & $256(68)$ \\
\hline M2 & Botanical gardens/White Trail & $33^{\circ} 54^{\prime} 30.96^{\prime \prime} \mathrm{N}, 83^{\circ} 22^{\prime} 52.85^{\prime \prime} \mathrm{W}$ & 0 & 150 & 96 & 0.433 & $651(57)$ \\
\hline M3 & Botanical gardens/Callaway Building & $33^{\circ} 54^{\prime} 1.09^{\prime \prime} \mathrm{N}, 83^{\circ} 23^{\prime} 8.15^{\prime \prime} \mathrm{W}$ & 0 & 300 & 110 & 0.489 & $666(41)$ \\
\hline M4 & Heritage Park & $33^{\circ} 44^{\prime} 22.74^{\prime \prime} \mathrm{N}, 83^{\circ} 26^{\prime} 2.57^{\prime \prime} \mathrm{W}$ & 0 & $>1500$ & - & - & - \\
\hline \multicolumn{8}{|c|}{ Dimorphic populations } \\
\hline D1 & Botanical gardens/Orange Trail & $33^{\circ} 54^{\prime} 4.92^{\prime \prime} \mathrm{N}, 83^{\circ} 22^{\prime} 47.34^{\prime \prime} \mathrm{W}$ & 50 & $>1500$ & 200 & 2.27 & $200(4)$ \\
\hline D2 & Botanical gardens/Orange Trail Gully & $33^{\circ} 54^{\prime} 4.90^{\prime \prime} \mathrm{N}, 83^{\circ} 22^{\prime} 44.93^{\prime \prime} \mathrm{W}$ & 50 & 300 & 200 & 0.480 & $475(41)$ \\
\hline D3 & Memorial Park & $33^{\circ} 55^{\prime} 38.15^{\prime \prime} \mathrm{N}, 83^{\circ} 23^{\prime} 7.21^{\prime \prime} \mathrm{W}$ & 33 & $>1800$ & 183 & 11.849 & $103(2)$ \\
\hline
\end{tabular}


Table 2 Mating system parameters including multilocus selfing rate $\left(s_{\mathrm{m}}\right)$, biparental inbreeding $\left(b=t_{\mathrm{m}}-t_{\mathrm{s}}\right)$, the calculated primary selfing rate $\left(s_{\mathrm{Z}}\right)$ and primary biparental inbreeding rate $\left(b_{\mathrm{Z}}\right)$, and the female fitness advantage gained through lack of selfing $\left(F A_{S}\right)$ and biparental inbreeding differences $\left(F A_{S}+B I\right)$

\begin{tabular}{|c|c|c|c|c|c|c|c|c|}
\hline Population & $\mathrm{N}_{\text {fam }}$ & $\mathrm{N}_{\text {seeds }}$ & $\mathrm{s}_{m}(95 \% \mathrm{Cl})$ & b $(95 \% \mathrm{Cl})$ & $\mathrm{s}_{z}$ & Female $F A_{S}$ & $\mathrm{~b}_{z}$ & Female $F A_{S+B I}$ \\
\hline \multicolumn{9}{|c|}{ Monomorphic populations } \\
\hline \multicolumn{9}{|c|}{ M3 } \\
\hline Hermaphrodites & 16 & 229 & $-0.015(-0.200$ to 0.045$)$ & $-0.001(-0.055$ to 0.120$)$ & & & & \\
\hline Females & 31 & 311 & $0.057(-0.079$ to 0.146$)$ & $-0.020(-0.050$ to 0.094$)$ & & 1.01 & -0.022 & 1.14 \\
\hline Hermaphrodites & 19 & 150 & $0.008(-0.200$ to 0.231$)$ & $0.182(0.047$ to 0.361$)$ & 0.013 & & 0.211 & \\
\hline \multicolumn{9}{|l|}{ D3 } \\
\hline Females & 17 & 274 & $0.000(-0.117$ to 0.055$)$ & $0.035(-0.113$ to 0.119$)$ & & 1.14 & 0.059 & 1.11 \\
\hline Hermaphrodites & 17 & 288 & $0.047(-0.025$ to 0.113$)$ & $0.004(-0.048$ to 0.069$)$ & 0.141 & & 0.006 & \\
\hline
\end{tabular}

Abbreviation: $\mathrm{Cl}$, confidence interval.

$N_{\text {fam }}=$ number of families used and $N_{\text {seeds }}=$ total number of seeds genotyped.

number of plants. For populations with too many individuals within transects (D1 and D3), a random subset of individuals were sampled. Plants used in the genetic structure analyses were mapped to the nearest $\mathrm{cm}$ by stretching a meter tape down the length of a transect and measuring the distance from the plant to the tape with a meter stick perpendicular to the tape. Locations were then converted to $(x, y)$ co-ordinates to allow analysis of spatial genetic structure.

\section{Genotyping}

Seeds (for mating system analysis) and leaves (for spatial genetic structure analysis) were crushed and their enzymes extracted using the extraction buffer of Wendel and Parks (1982). Protein extracts were absorbed onto $4 \times 6$-mm wicks punched from Whatman $3 \mathrm{~mm}$ chromatography paper and stored at $-70{ }^{\circ} \mathrm{C}$ for later electrophoretic analysis.

Eleven or twelve polymorphic allozyme loci were resolved for each population for the mating system analyses and eight loci were resolved for the genetic structure analyses. Wicks were placed in $10 \%$ starch gels for electrophoresis, and enzyme stains were resolved on one of four buffer systems adapted from Soltis et al. (1983), Cheliak and Pitel (1984) or Manchenko (1994): buffer system 8- (stains DIA1, DIA2, FE1, FE3, AAT), system MC (UGPP, F-16, LAP), system 4 (PGM1, PGM2, IDH1, IDH2, LAP) and system $11(\mathrm{MDH} 2, \mathrm{PGI})$. Owing to different levels of enzyme activity, some loci were not scorable for a portion of the individuals. To avoid biasing our analyses due to missing data, we removed individuals or loci that were missing $30 \%$ of the genotypic data from the spatial genetic structure analysis of that population (number removed: $\mathrm{M} 1=19, \mathrm{M} 2=1, \mathrm{D} 1=10$ and $\mathrm{D} 3=29$ ). In addition, we identified and removed clonal ramets as individuals that had the same multilocus genotype, sex, and were within $1 \mathrm{~m}$ of each other (number removed: $\mathrm{M} 1=16, \mathrm{M} 2=5, \mathrm{D} 1=28$ and $\mathrm{D} 3=30$ ).

\section{Mating system analysis}

To determine the extent of selfing in hermaphrodites, the biparental inbreeding rate in females and hermaphrodites, and whether these rates differed by population type, several mating system parameters were estimated. These parameters included the multilocus outcrossing rate $\left(t_{\mathrm{m}}\right)$ and the mean singlelocus outcrossing rate $\left(t_{\mathrm{s}}\right)$, which were then used to calculate the selfing rate $\left(s_{\mathrm{m}}=1-t_{\mathrm{m}}\right)$ and biparental inbreeding rates $\left(b=t_{\mathrm{m}}-t_{\mathrm{s}}\right)$ for females and hermaphrodites. Selfing rates for females should be zero; however, it is possible to get a non-zero value if variation in the genetic markers is not sufficient to completely distinguish selfing from biparental inbreeding (Brown, 1990). For each measure, 1000 bootstraps were used to obtain 95\% confidence intervals, which were used to determine whether selfing was significantly different from zero and to compare between populations. To compare estimates between sexes within the same population, we coded the female mothers and hermaphrodite mothers as different groups, which allowed a statistical comparison between the two groups by resampling the data and determining the s.d. of the difference between the groups. Values were considered to be significant if the actual difference was greater than twice the s.d. All parameters were calculated using MLTR v.3.4, which uses a maximum likelihood technique for mating system parameter estimation (Ritland, 2002). Data from both germinated and ungerminated seeds were included in the analyses. Removing germinated seeds from the analyses increased the outcrossing rate slightly, but did not change the relationship between sexes.

To account for early acting inbreeding depression, we also calculated the primary selfing rate (Maki, 1993) and primary biparental inbreeding rate that represent estimates of the rates immediately following pollination and prior to seed abortion due to early acting inbreeding depression. We used cumulative predispersal estimates of inbreeding depression from Chang (2007), which was calculated using the number of seeds produced per pollination. To calculate primary selfing rates for hermaphrodites $\left(\mathrm{s}_{\mathrm{z}}\right)$, population-specific estimates of inbreeding depression in seed production for D1 and D3 (cumulative predisperal inbreeding depression $\delta_{\text {pre }}=0.40$ and 0.70 , respectively; Chang, 2007) were used in the following calculation: $s_{\mathrm{z}}=s /\left(1-\delta_{\text {pre }}+s \delta_{\text {pre }}\right)$. Similarly, to calculate primary biparental inbreeding rates for both females and hermaphrodites $\left(b_{\mathrm{z}}, b_{\mathrm{zH}}\right.$, respectively), population and sex-specific estimates of biparental inbreeding depression were used for example, $b_{\mathrm{zF}}=b_{\mathrm{F}} /\left(1-\delta_{\mathrm{bF}}+\right.$ $\left.b_{\mathrm{F}} \delta_{\mathrm{bF}}\right)$ with D1: $\delta_{\mathrm{bF}}=0.09, \delta_{\mathrm{bH}}=0.17 ; \mathrm{D} 3: \delta_{\mathrm{bF}}=0.42, \delta_{\mathrm{bH}}=0.37$ (Chang, 2007).

To determine the FA that females gained through inbreeding avoidance, we combined the selfing rates of hermaphrodites with previously estimated inbreeding depression. Although not a lifetime measure of cumulative inbreeding depression, Chang (2007) measured inbreeding depression through two years, from which we calculated cumulative inbreeding depression as: $\delta=1-\left(1-\delta_{\text {predispersal }}\right) \times\left(1-\delta_{\text {postdispersal }}\right)$ for each population resulting in D1: $\delta=0.86, \mathrm{D} 3: \delta=0.88$. From these measures of inbreeding depression, FA was calculated as: $\mathrm{FA}=1 /\left(1-s_{z} \delta\right)$ for each dimorphic population. We also calculated the female advantage including biparental inbreeding as $\mathrm{FA}_{\mathrm{S}}+$ $\mathrm{BI}=\left(1-b_{\mathrm{zF}} \delta_{\mathrm{bF}}\right) /\left(1-s_{\mathrm{z}} \delta-b_{\mathrm{zH}} \delta_{\mathrm{bH}}\right)$, where $b_{\mathrm{zF}}$ and $b_{\mathrm{zH}}$ are the primary biparental inbreeding rates of females and hermaphrodites, respectively, and $\delta_{\mathrm{bF}}$ and $\delta_{\mathrm{bH}}$ are the calculated cumulative biparental inbreeding depression rates for females and hermaphrodites derived from Chang (2007) as above: D1: $\delta_{\mathrm{bF}}=0.55, \delta_{\mathrm{bH}}=0.49 ; \mathrm{D} 3: \delta_{\mathrm{bF}}=0.49, \quad \delta_{\mathrm{bH}}=0.66$. These estimates of FA assume equal reproductive potential between sexes (for example, similar numbers of ovules per plant), which has generally been found in this species under natural conditions (Ågren and Willson 1991; Chang 2006; Van Etten and Chang unpublished). 


\section{Spatial genetic structure analysis}

We analyzed spatial genetic structure within populations using correlograms, which characterize the genetic relationship between pairs of individuals separated by various distances (Ennos, 2001). Genetic relatedness was calculated using the multilocus autocorrelation coefficient, $r$, described in Smouse and Peakall (1999). This coefficient is bounded by one and negative one, with positive values indicating that individuals are more related than expected by chance given the allele frequencies in the population, and negative values indicating that individuals are less related than expected by chance. For each distance class, mean genetic relatedness between pairs of individuals at that distance class is calculated, and tested to see if it is significantly different from zero by bootstrapping the genotypes. A relatedness value of 0.5 represents pairs whose relatedness is equivalent to full sibs and 0.25 is equivalent to halfsibs. Genetic structure was tested using GenAlEx v.6 (Peakall and Smouse, 2006).

To allow comparisons with other species, several other indices were calculated. The $S p$ statistic, which essentially measures the rate of decrease of spatial genetic structure with distance, was calculated for each population and averaged (Vekemans and Hardy, 2004). It was calculated as $b /\left(F_{1}-1\right)$, where $b$ was the slope of the decrease in relatedness over the logarithm of the distance between pairs up to $500 \mathrm{~cm}$ and $\mathrm{F}_{1}$ was the relatedness at the first distance class calculated according to Loiselle et al. (1995). All analyses involving Sp were performed using SPAGeDi v1.1 (Hardy and Vekemans, 2002). Population genetic parameters were calculated using GenAlEx (Peakall and Smouse, 2006), including observed and expected heterozygosity $\left(H_{\mathrm{o}}, H_{\mathrm{e}}\right.$, respectively) and the proportion of genetic diversity found among populations ( $F_{\mathrm{ST}}$; Supplementary Table S1).

\section{RESULTS}

\section{FA gained from inbreeding avoidance}

The selfing rate was not significantly greater than zero in any population. The estimated selfing rate of hermaphrodites ranged from -14.0 to $4.7 \%$ (Table 2). Non-negative values of selfing were only found in hermaphrodites in dimorphic populations (D1: $\left.s_{\mathrm{m}}=0.008 ; \mathrm{D} 3: s_{\mathrm{m}}=0.047\right)$. After accounting for early abortion of selfed seeds, primary selfing rates were estimated to be $1.3 \%$ and $14.1 \%$ in D1 and D3 hermaphrodites, respectively. The combination of primary selfing rates and previously measured inbreeding depression led to a female FA of 1.01-1.14 through inbreeding (depression) avoidance in the dimorphic populations.

\section{Spatial genetic structure and biparental inbreeding}

All populations showed significant spatial genetic structure at short distances (Figure 1). Across all populations, average relatedness between pairs of individuals that were $75 \mathrm{~cm}$ apart (the smallest distance class) was 0.216 , approximately that of half-sibs. The $S p$ ranged from 0.031 to 0.109 , with an average of 0.050 (Figure 1).

Despite significant spatial genetic structure, biparental inbreeding rates were low (average of $5.2 \%$; Table 2) and only differed significantly from zero in hermaphrodites in population D3. Calculating the primary biparental inbreeding rates for the dimorphic populations slightly increased the estimates to a maximum of $21.1 \%$.

\section{Differences in biparental inbreeding}

Biparental inbreeding rates of hermaphrodites were significantly higher than those of females in the D1 population (difference $=0.202$, s.d. $=0.098$ ) but not in the D3 population (difference $=0.031$, s.d. $=0.067)$. Including this sex difference in the calculation of the female FA resulted in a slight increase (1.01 from only selfing vs 1.14 from selfing and biparental inbreeding).

\section{DISCUSSION}

How much FA do females gain through inbreeding avoidance and is it enough to explain their maintenance?

Despite the high levels of inbreeding depression found in a previous study (Chang, 2007), the resulting advantage for females through inbreeding avoidance is small owing to low levels of selfing in hermaphrodites. Both the measured seed selfing rate $(0.8-5 \%$ for dimorphic populations) and the estimated primary selfing rate (1$14 \%$ ) are low compared with the average of $30-50 \%$ selfing found in other gynodioecious species (Collin and Shykoff, 2003). Whether the resulting $1.01-1.14 \times$ advantage is enough to maintain females depends on the genetic control of sex. If sex is under nuclear control, a $2 \times$ advantage is needed for females to be maintained (Charlesworth and Charlesworth, 1978), and thus, inbreeding avoidance would not be enough to explain female maintenance. Requirements for female maintenance if sex is under cyto-nuclear control (male-sterility determined by a cytoplasmic gene and male fertility
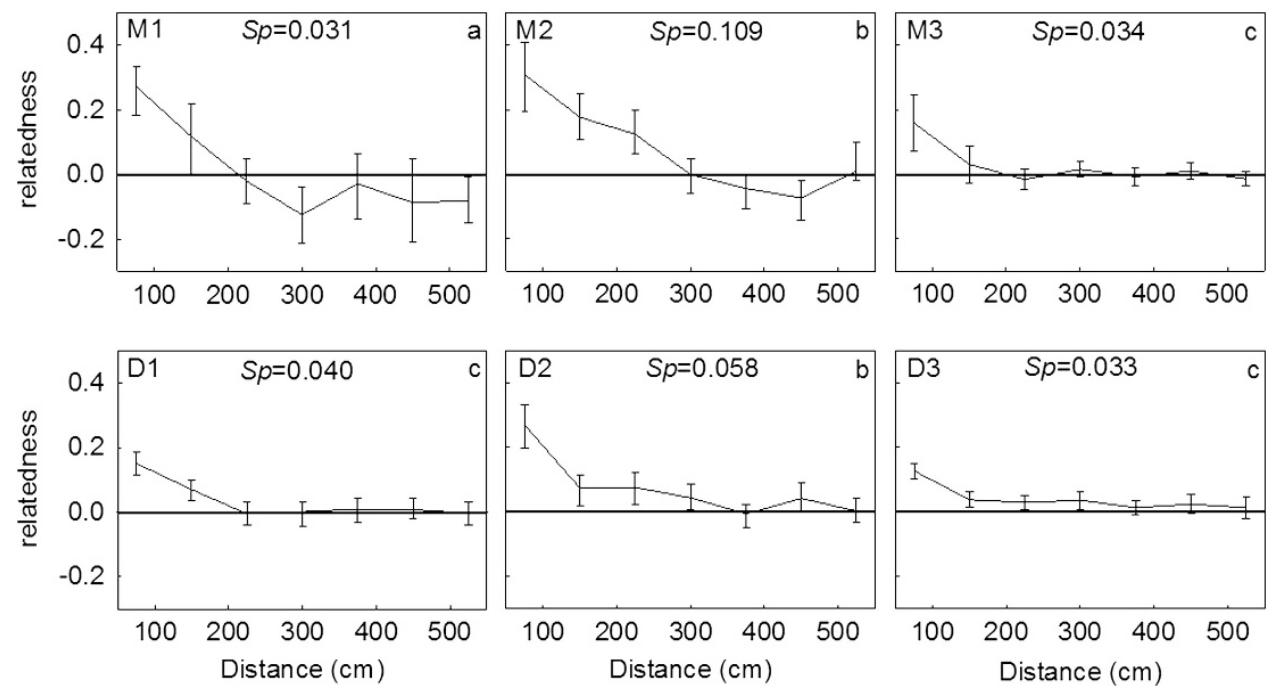

Figure 1 All populations (labeled in the upper left hand corner) showed significant spatial genetic structure as shown by significant relatedness values (bootstrap confidence interval not overlapping zero) and non-zero $S p$ values. Populations sharing a letter in the upper right hand corner of the correlogram are not significantly different from each other. 
restored by a nuclear gene) are more complex, but can be as low as slightly $>1 \times$ when the cost of having the restorer allele is high (Gouyon et al., 1991; Bailey et al., 2003). Thus, if sex is under cytonuclear control, the advantage we found could be enough to maintain females, but only if restoration costs were high. A study to understand the genetic control of sex determination in G. maculatum is underway.

Does spatial genetic structure occur within populations and does this lead to biparental inbreeding?

We found significant spatial genetic structure at the smallest distance classes. Pairs of individuals within $75 \mathrm{~cm}$ distance had an average relatedness of slightly less than that of half-sibs. $S p$ values ranged from 0.031 to 0.109 , which is similar to those found in species with mixed mating (0.0372) or herbaceous life forms (0.0459), but slightly higher than species with animal dispersed pollen (0.0171; Vekemans and Hardy, 2004). Several other studies have examined fine-scale genetic structure in gynodioecious species, with varying results. Structure of mitochondrial haplotypes was found in few populations and only at distances $<2 \mathrm{~m}$ in Silene acaulis, a long-lived, insect pollinated, perennial with gravity dispersed seeds (Klass and Olson, 2006). The authors suggested that the lack of structure could be due to long distance wind dispersal of seeds or few available unoccupied habitats. Interestingly, De Cauwer et al. (2010) found differing patterns of structure within a single population of Beta vulgaris, a short-lived, wind pollinated, perennial with gravity dispersed seeds. Bayesian analysis suggested that the population consisted of two groups, which the authors speculated to be due to historical restriction of pollen and seed dispersal. In one group, both cytoplasmic $(S p=0.3186)$ and nuclear markers (0.0171) had significant structure, whereas the other group had very little $(0.0168,0.005$, respectively). Results from these studies suggest that idiosyncratic species traits and localized conditions could be important in creating spatial structure, and therefore, generalizations across gynodioecious species may not be possible.

Despite significant spatial genetic structure, biparental inbreeding was low overall and ranged from 0 to $18.2 \%$. Accounting for possible early biparental inbreeding depression found in the dimorphic populations in a previous study (Chang, 2007) increased the rates to at most $21.1 \%$. Our rates of biparental inbreeding are similar to those found in other gynodioecious species, ranging from 0 to $31 \%$ (Figure 2, Supplementary Table 2). In gynodioecious species, two methods have been used to estimate biparental inbreeding rates and produce different estimates. First, because females are necessarily outcrossed, any selfing rate greater than zero should be from undetectable biparental inbreeding, which results in a range from 0 to $26 \%$ across gynodioecious species (Figure 2a). Second, the common method of subtracting the multilocus selfing rate from the single-locus selfing rate resulted in a range of $0-31 \%$ biparental inbreeding (Figure 2b). These values are not outside of the normal range of values for plant species. For example, Brown (1990) found a range of $0-15 \%$ biparental inbreeding across a variety of species, with an average of $3.6 \%$.

Do differences in biparental inbreeding affect female maintenance? As both females and hermaphrodites can inbreed biparentally, relative female seed fitness will only be affected if the sexes differ in their biparental inbreeding rates or the severity of biparental inbreeding depression. For G. maculatum, Chang (2007) found that the sexes didn't differ in the severity of biparental inbreeding depression ( $P=0.41$, Chang, 2007). However, in population D1, hermaphrodites had significantly higher biparental inbreeding rates than females $(18.2 \%$ vs $-2.0 \%)$. Despite this large difference and relatively high biparental inbreeding depression $\left(\delta_{\mathrm{b}}=0.49-0.66\right.$; Chang, 2007), because the overall biparental inbreeding rates are low, the effect on female advantage was small-increasing from 1.01 to 1.14. Several studies have suggested that biparental inbreeding rates estimated from a mating system analysis, as presented here, can potentially underestimate actual rates because these estimates depend on the number and variability of loci used to adequately distinguish between progeny from selfing versus biparentally inbreeding (Leclerc-Potvin and Ritland 1994; Ritland, 2002; Griffin and Eckert, 2003). Because of the high number and the decent variability (Supplementary Table S1) of loci we used in this study, our estimates are unlikely to have suffered significantly from such bias. In addition, given the extremely low selfing rates in hermaphrodite and the moderate level of
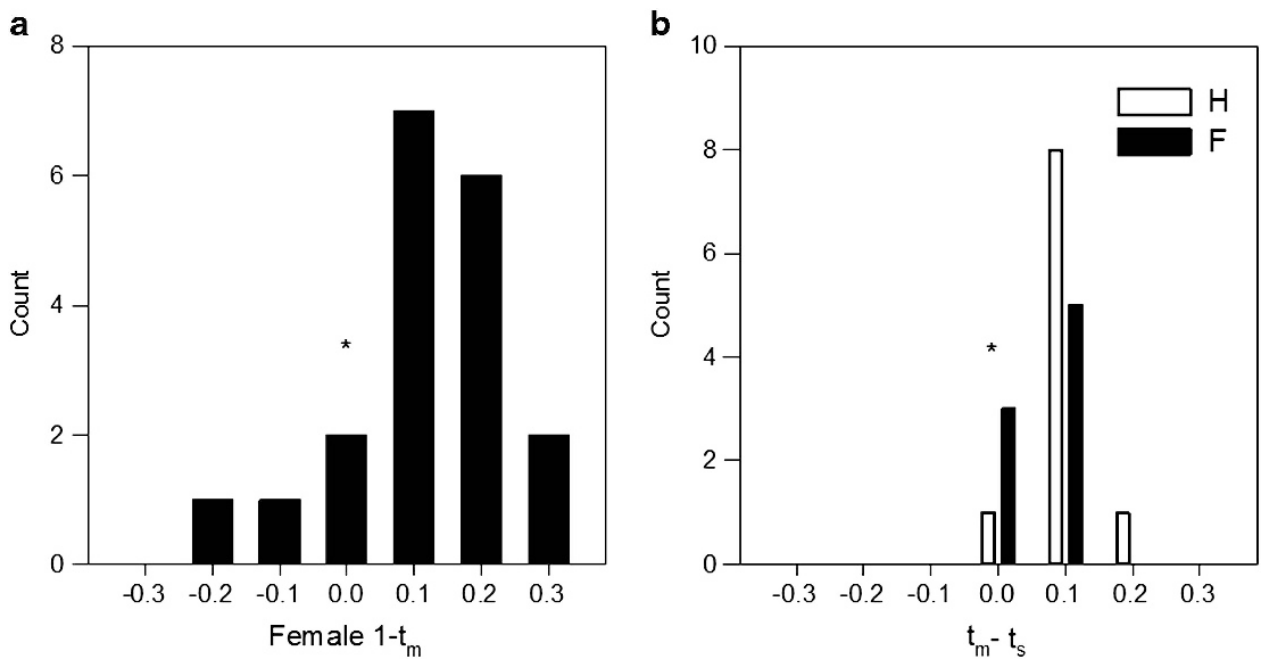

Figure 2 Distribution of average biparental inbreeding rates found in previous studies of gynodioecious species. Values were estimated from either (a) Female selfing rates $\left(1-t_{m}\right)$ or $(\mathbf{b}) t_{m}-t_{\mathrm{s}}$ from hermaphrodites $(\mathrm{H})$ or females $(\mathrm{F})$. Asterisks show the values obtained in this study. 
biparental inbreeding depression, it would take a very large difference in biparental inbreeding rates to substantially affect the female FA. For example, it would take a biparental inbreeding rate of $67 \%$ for hermaphrodites and $0 \%$ for females to bring female's relative seed fitness to be $1.5 \times$ of hermaphrodite's fitness. Combined, there is little support that biparental inbreeding could have significantly affected the magnitude of female FA in G. maculatum

Studies in which biparental inbreeding rates were measured for both females and hermaphrodites show no consistent pattern of differences between the sexes (Figure 2; Supplementary Table S2). Including this study, 3 of 10 studies showed females had significantly lower biparental inbreeding than hermaphrodites in at least one population, whereas the rest of the studies showed no significant differences. These studies suggest that the drastically different levels of biparental inbreeding needed to affect relative female fitness are not pervasive among gynodioecious species, and therefore may not have a large role in mating system evolution.

\section{Implications for the evolution of gynodioecy}

Although inbreeding avoidance is one of the two common hypotheses regarding how females are maintained, a recent review showed it had a large role in only 7 of 18 self-compatible species (Dufay and Billard, 2012). Our results seem to support this trend; we found that the low selfing rate in hermaphrodites led to G. maculatum females gaining only a $1-14 \%$ increase in fitness through avoiding inbreeding. If sex is under nuclear control, a 100\% fitness increase in females is needed, which is clearly not gained through inbreeding avoidance alone. Additional fitness increases could be gained if females had lower rates of biparental inbreeding. However, despite considerable spatial genetic structure, biparental inbreeding rates were low and only different between sexes in one population. In this population, despite a higher biparental inbreeding rate, the increase gained by females was incremental. This negligible effect of biparental inbreeding may be ubiquitous across gynodioecious species as our literature review of biparental inbreeding rates showed low rates that rarely differed between sexes. These observations suggest that instead of the mating system being the primary factor in the evolution and maintenance of females, other mechanisms, for example, context dependent selection (Ashman and Diefenderfer, 2001; Case and Ashman, 2007; Dufay et al., 2009) or biotic interactions such as herbivory (Ashman, 2002) and mychorrizal associations (Pendleton, 2000; Varga, 2010; Varga et al., 2013), may be more important in many gynodioecious species, including G. maculatum.

\section{DATA ARCHIVING}

Data available from the Dryad Digital Repository: doi:10.5061/ dryad.p3f13.

\section{CONFLICT OF INTEREST}

The authors declare no conflict of interest.

\section{ACKNOWLEDGEMENTS}

We thank K O'Neal for help with mapping the populations and L Donovan, LC Brouillette, A Howard, S Gevaert, R Shirk, D Christopher and S Pearl for their helpful comments on the manuscript. This research was supported by the Plant Biology Department at the University of Georgia (Student Research Grant to MLV and ACD) and by National Science Foundation grant DEB-0640881 to SMC.
Ågren J, Willson MF (1991). Gender variation and sexual differences in reproductive characters and seed production in gynodioecious Geranium maculatum. Am J Bot 78: 470-480.

Ashman TL (2002). The role of herbivores in the evolution of separate sexes from hermaphroditism. Ecology 83: 1175-1184.

Ashman TL, Diefenderfer C (2001). Sex ratio represents a unique context for selection on attractive traits: consequences for the evolution of sexual dimorphism. Am Nat 157: 334-347.

Bailey MF, Delph LF, Lively CM (2003). Modeling gynodioecy: novel scenarios for maintaining polymorphism. Am Nat 161: 762-776.

Barrett SCH (2010). Understanding plant reproductive diversity. Phil Trans $R$ Soc B 365: 99-109.

Brown AHD (1990). Genetic characterization of plant mating systems. In: Brown AHD, Clegg MT, Kahler AL, Weir BS (eds) Plant population genetics, breeding and genetic resources. Sinauer: Sunderland, pp 145-162.

Case AL, Ashman TL (2007). An experimental test of the effects of resources and sex ratio on maternal fitness and phenotypic selection in gynodioecious Fragaria virginiana. Evolution 61: 1900-1911.

Chang S-M (2006). Female compensation through the quantity and quality of progeny in a gynodioecious plant, Geranium maculatum (Geraniaceae). Am J Bot 93: 263-270.

Chang S-M (2007). Gender-specific inbreeding depression in a gynodioecious plant, Geranium maculatum (Geraniaceae). Am J Bot 94: 1193-1204.

Charlesworth B, Charlesworth D (1978). Model for evolution of dioecy and gynodioecy. Am Nat 112: 975-997.

Cheliak WM, Pitel JA (1984). Techniques for starch gel electrophoresis of enzymes from forest tree species. In:Petawawa National Forestry Institute(ed) Information report P1$X$-42. Canadian Forestry Service: Ontario.

Collin CL, Shykoff JA (2003). Outcrossing rates in the gynomonoecious-gynodioecious species Dianthus sylvestis (Caryophyllaceae). Am J Bot 90: 579-585.

Darwin C (1897). The different forms of flowers on plants of the same species. D. Appleton and Company: New York, NY, USA

De Cauwer I, Dufay M, Cuguen J, Arnaud J-F (2010). Effects of fine-scale genetic structure on male mating success in gynodioecious Beta vulgaris ssp. maritima. Mol Ecol 19: $1540-1558$.

De Cauwer I, Dufay M, Hornoy B, Courseaux A, Arnaud J-F (2012). Gynodioecy in structured populations: understanding fine-scale sex ratio variation in Beta vulgaris ssp. maritima. Mol Ecol 21: 834-850.

Delph LF (2004). Testing for sex differences in biparental inbreeding and its consequences in a gynodioecious species. Am J Bot 91: 51 .

Dufay M, Billard E (2012). How much better are females? The occurrence of female advantage, its proximal causes and its variation within and among gynodioecious species. Ann Bot 109: 505-519.

Dufay M, Cuguen J, Arnaud JF, Touzet P (2009). Sex ratio variation among gynodioecious populations of sea beet: can it be explained by negative frequency-dependent selection? Evolution 63: 1483-1497.

Ennos RA (2001). Inferences about spatial processes in plant populations from the analysis of molecular markers. In: Silvertown J, Antonovics J (eds) Integrating Ecology and Evolution in a Spatial Context. Blackwell Publishing: Williston, ND, USA, pp 45-72.

Epperson BK (1993). Recent advances in correlation studies of spatial patterns of genetic variation. In: Hecht MK, MacIntyre RJ, Clegg MT (eds) Evolutionary Biology. Springer: New York, NY, USA. Vol 27, pp 95-155.

Glaettli M, Goudet J (2006). Variation in the intensity of inbreeding depression among successive life-cycles stages and generations in gynodioecious Silene vulgaris (Caryophyllaceae). J Evol Biol 19: 1995-2005.

Gouyon PH, Vichot F, Van Damme JMM (1991). Nuclear-cytoplasmic male sterility: singlepoint equilibria versus limit cycles. Am Nat 137: 498-514.

Griffin CAM, Eckert CG (2003). Experimental analysis of biparental inbreeding in a selffertilizing plant. Evolution 47: 1513-1519.

Hardy OJ, Vekemans X (2002). SPAGEDI: a versatile computer program to analyse spatial genetic structure at the individual or population levels. Mol Ecol Notes 2: 618-620.

Heywood JS (1991). Spatial analysis of genetic variation in plant populations. Annu Rev Ecol Syst 22: 335-355.

Klass AL, Olson MS (2006). Spatial distributions of cytoplasmic types and sex expression in Alaskan populations of Silene acaulis. Int J Plant Sci 167: 179-189.

Kohn JR, Biardi JE (1995). Outcrossing rates and inferred levels of inbreeding depression in gynodioecious Cucurbita foetidissima (Cucurbitaceae). Heredity 75: 77-83.

Leclerc-Potvin C, Ritland K (1994). Modes of self-fertilization in Mimulus guttatus (Scrophulariaceae): a field experiment. Am J Bot 81: 199-205.

Loiselle BA, Sork VL, Nason J, Graham C (1995). Spatial genetic structure of a tropical understory shrub, Psychotria officinalis (Rubiaceae). Am J Bot 82: 1420-1425.

Maki M (1993). Outcrossing and fecundity advantage of females in gynodioecious Chionographis japonica var. kurohimensis (Liliaceae). Am J Bot 80: 629-634.

Manchenko GP (1994). Handbook of detection of enzymes on electrophoretic gels. CRC Press: Ann Harbour.

Miyake K, Olson MS (2009). Experimental evidence for frequency dependent self-fertilization in the gynodioecious plant, Silene vulgaris. Evolution 63: 1644-1652.

Mutikainen P, Delph LF (1998). Inbreeding depression in gynodioecious Lobelia siphilitica: among family differences override between-morph differences. Evolution 52: 1572-1582.

Olson MS, Graf AV, Niles KR (2006). Fine scale spatial structuring of sex and mitochondria in Silene vulgaris. J Evol Biol 19: 1190-1201. 
Peakall R, Smouse PE (2006). GenAIEx 6: genetic analysis in excel. Population genetic software for teaching and research. Mol Ecol Notes 6: 288-295.

Pendleton R (2000). Pre-inoculation by an arbuscular mycorrhizal fungus enhances male reproductive output of Cucurbita foetidissima. Int J Plant Sci 161: 683-689.

Ritland K (2002). Extensions of models for the estimation of mating systems using an independent loci. Heredity 88: 221-228.

Shykoff JA, Kolokotronis SO, Collin CL, Lopez-Villavicencio M (2003). Effects of male sterility on reproductive traits in gynodioecious plants: a meta-analysis. Oecologia 135: 1-9.

Smouse PE, Peakall R (1999). Spatial autocorrelation analysis of individual multiallele and multilocus genetic structure. Heredity 82: 561-573.

Soltis DE, Haufler CH, Darrow DC, Gastony GJ (1983). Starch gel electrophoresis of fernsa compilation of grinding buffers, gel and electrode buffers, and staining schedules. Am Fern J 73: 9-27.
Stamp NE, Lucas JR (1983). Ecological correlates of explosive seed dispersal. Oecologia 59: 272-278.

Van Etten ML, Chang S-M (2009). Effects of environmental heterogeneity on the distribution of sexes within and among populations in a gynodioecious species, Geranium maculatum. New Phytol 183: 649-660.

Varga S (2010). Effects of arbuscular mycorrhizas on reproductive traits in sexually dimorphic plants. Span J Agric Res 8: S11-S24.

Varga S, Vega-Frutis R, Kytoviita MM (2013). Transgenerational effects of plant sex and arbuscular mycorrhizal symbiosis. New Phytol 199: 812-821.

Vekemans X. Hardy OJ (2004). New insights from fine-scale spatial genetic structure analyses in plant populations. Mol Ecol 13: 921-935.

Wendel JF, Parks CR (1982). Genetic control of isoenzyme variation in Camellia japonica L. J Hered 73: 197-204.

Supplementary Information accompanies this paper on Heredity website (http://www.nature.com/hdy) 